\title{
Double Dividend from Tariff Differentiation of Reforestation Fund
}

\author{
Sudarsono Soedomo \\ Department of Forest Management, Faculty of Forestry, Bogor Agricultural University, Academic Ring Road, Campus IPB \\ Dramaga, PO Box 168, Bogor 16680, Indonesia
}

Received May 23, 2013/Accepted July 17, 2013

\begin{abstract}
Distortionary levy applied uniformly to all diameter classes of logs from logging natural forest can lead to inefficiencies; certain diameter should be left in the field because it is not economical to be used. Win-win or Pareto improving solution can be achieved if the government is more flexible. Social welfare is higher because of the waste that can be utilized to create employment, production and additional benefits for employers, as well as revenue for the state. Even if the levy rates are forced to zero for small-diameter timber, governments is actually not harmed at all because from the beginning the government does not get any revenue from small timber that is left in the field as waste. In scarcity situations of timber from natural forests, it is desirable if the government is considering differentiating charges in order to reduce or possibly eliminate the volume of waste generated by the levy. In general, tariff differentiation done in the form of higher tariffs for higher diameter logs. If possible, the lowest diameter limit of logs is forced down to its technical limits. That is, the processing tool that will determine how the minimum diameter logs can be processed profitably.
\end{abstract}

Keywords: tariff differentiation, efficiency, timber utilization, government revenue, win-win solution

*Correspondence author,email: ssoedomo@gmail.com,telp.+62-251-862-1256

\section{Introduction}

Charges against the forest can be used to influence the rate of harvesting, harvest acreage, species harvested, and the level of timber utilization (Gray 1983). A phenomenon that frequently occurs is over-logging in areas that are near or easily accessible as a result of the lack of charges reflecting differences in stumpage value arising from differences in accessibility. Similar findings delivered by Hyde and Sedjo (1992) which states that a uniform extraction fee is often lower revenues and encourage behavior of harvesting highvalue timber only. Levy taking into account heterogeneity of quality wood can be used to suppress the behavior of highgrading (Paarsch 1993). From the social and the environment points of view, many economists agree that forest management in Indonesia is the big disaster (Poffenberger 1997).

Royalties derived from the extraction of natural resources is an important source of state revenue. However, the structure of the forest royalties could lead to deforestation through unsustainable harvesting and focus on high-quality timber only (Amacher et al. 2001). Royalty structure also affects the efficiency of logs utilization. The low rents collected by the government could cause logging profit becomes so high that encourages excessive investment (World Bank 2004).

According to its effect, taxes or any other levies imposed by the government can be grouped into 2 categories, namely taxes or levies that are distortionary and taxes or levies that are not distortionary. Distortionary taxes or levies may affect the efficiency of resource allocation, both in positive and negative direction. Distortionary taxes or levies having the effect of lowering the production is very understandable. But if the decline in production increased significantly wasted wood unnecessarily, especially in conditions of increasing timber scarcity, the distortionary effect needs more serious attention. Reforestation fund (DR) and forest resource provision (PSDH) are the 2 types of charges in forestry that are distortionary.

A uniform rate of DR and PSDH for all diameter classes of logs from natural forest causes small diameter logs to become inefficient to be used. Log diameter is one of heterogeneity elements that has to be considered in determining the rates of DR and PSDH. Since the Presidential Decree No 40 of 1993 DR rate differentiation has occurred, which is based on the areas of production, type of wood, and the type of product.

The purpose of this article is to show that the differentiation of charges in forestry according to $\log$ diameter classes potentially increase social welfare and state revenue. Increasing state revenues without reducing efficiency or even increases it becomes important when it is confronted with the fact that the Indonesian government received only $17 \%$ of the forest rents, whereas from the oil the rent collected by the government can reach $85 \%$ (Broad 1995). The review will be limited to DR. To that end, Section 2 will discuss a brief history of the birth of the Reforestation Fund. Section 3 deliver economic analysis determining the minimum diameter, which is then followed 
by Section 4 which discusses policy implications. Finally, Section 5 is the conclusion.

\section{Short History of Reforestation Fund}

When someone is asked "What is the Reforestation Fund or commonly known as DR"? The most likely and the quickest move are to recall the definition of DR in Regulation 6 of 2007 which states that the DR is a fund collected from IUPHHK holders in natural production forest to reforest and rehabilitate forests. No matter how ridiculous the definition of DR is, but all parties must follow the official and legal definition of it. Being amused is just personal affairs, but obeying the laws and regulations is closely related to the public interest. When the questions are continued, what does DR actually reflect? The answer to this question has begun to diverge. Amplified with the question "is it true if DR is treated as non-tax state revenues (PNBP)?", then the debate will be lively.

Senior foresters, the ones who graduated from Indonesian schools of forestry prior to 1990 usually working as government officials, comprehend DR as metamorphose of (Dana Jaminan Reboisasi) (Reforestation Guarantee Fund). From name point of view, both DR and DJR have similarity and it is understandable if one sees that the 2 terms have a close relation. It is true, the initial money of DR was from the money of DJR. DJR was money that belongs to holders of forest concession right that must be deposited in the government's account as a performance guarantee of reforestation of forest area under their concession.

Through the Presidential Decree No 35 of 1980 regarding DJR, the holders of forest concession were required to deposit money to the government as guarantee for performing reforestation on their logged over areas. As time went by, DJR at the hand of the government built up because very few holders of forest concession who performed reforestation. Furthermore, the government through the Presidential Decree No 31 of 1989 regarding DR cancelled the Presidential Decree No 35 of 1980 and DJR was changed to DR with all consequences. The Presidential Decree No 31 of 1989 later on experienced many changes, e.g. through the Presidential Decree No 29 of 1990, the Presidential Decree No 28 of 1991, the Presidential Decree No 40 of 1993, and finally the Presidential Decree No 24 of 1997.

The legal status of the DR from 1989 to 1999 was not clear, whether or not it was the state revenue. Logically, state revenues are divided out into 2 categories, namely in the form of tax revenue and non-tax state revenue or known non-tax revenues. During the period 1989 to 1999 , DR was clearly not a tax nor non-tax revenues because inclusion of DR as a non-tax revenues lately occurred through Government Regulation No. 92 of 1999.

Large amounts of idle money certainly made many government bureaucrats tempt to use it. It follows the characteristics of bureaucracy that tends to maximize the budget (Niskanen 1968). To that end, the money must be first converted into money that belongs to the state to be used for reforestation. Thoughts like these that gave birth to the definition of DR containing high levels of awkwardness as set out in Regulation 6 of 2007. Is DR money only used to reforest unproductive forest areas? Public already knew what the answer to this question.

But when we look at the substance contained therein, DR and DJR has a much different meaning. DR is not a guarantee of performance, while DJR is a guarantee of performance. Act 41 of 1999 through Article 35 clearly mandates that every holder of IUPPH is charged with a performance bond (DJK). Is the mandate implemented by the Ministry of Forestry? So, in terms of substance, DJR was altered to DJK. Why did the word of "reforestation" more evolve into the collective memory than the word of "guarantee fund" so that people associated DJR more with DR than with DJK? Isn't "not executing law" a violation of the law itself?

There are 2 important questions related to reforestation. First, why did the licensees choose to sacrifice DJR and to hand over reforestation obligation to the government? Could it be because there is no need to be reforested because the licensees have worked with great care? The possibility is always there but the chances are too small. A more plausible reason is that the cost of reforestation is actually greater than DJR. Rational entrepreneur will surely give up DJR taken by the government in exchange for freedom from the obligation to conduct a reforestation. In other words, the amount of DJR set the government did not meet the participation constraint (see Laffont \& Martimort 2002). Second, if the private sector is not willing to carry out reforestation with risks such as loss of DJR, then by the same DJR private sector? Empirical devidence suggesting that government bureaucracies tend to be less efficient than private bureaucracies, then the answer to this second question is likely not possible. As a result, the damaged forest area will increase.

\section{Tariff Effect on Minimum Diameter}

Under situation of not vertically integrated with timber processing industries, the holders of forest concession must sell their timber production in free markets. It is assumed, for simplicity of exposition, that the unit price of logs is uniform and independent of the diameter, which is uniform for all diameter classes. Meanwhile, the production cost per cubic meter of logs decreased with increasing diameter. The intersection of the 2 curves will determine the minimum diameter of the logs that can be processed economically (Figure 1). The curve of the production cost per cubic meter of log without charges, DR, for example, is represented by the lower curve. This cost curve intersects the curve of the $\log$ prices at diameter of $\varnothing_{1}$. The existence of DR rates of $\tau_{1}$ per cubic meter makes the cost curve shift upward of $\tau_{1}$ and intersects the curve of $\log$ price at the diameter of $\varnothing_{2}$. If the DR rates are higher, such as $\tau_{2}$, then the intersection with the price of logs will occur at a higher diameter, that is, $\varnothing_{3}$. The result will not change if the log price is monotonically increasing with the diameter.

If we define the cumulative volume of logs of a certain diameter and greater is as follows (Equation [1]).

$$
V\left(\phi_{i}(\tau)\right)=\int_{\phi_{i}(\tau)}^{\infty} v(\phi) d \phi
$$




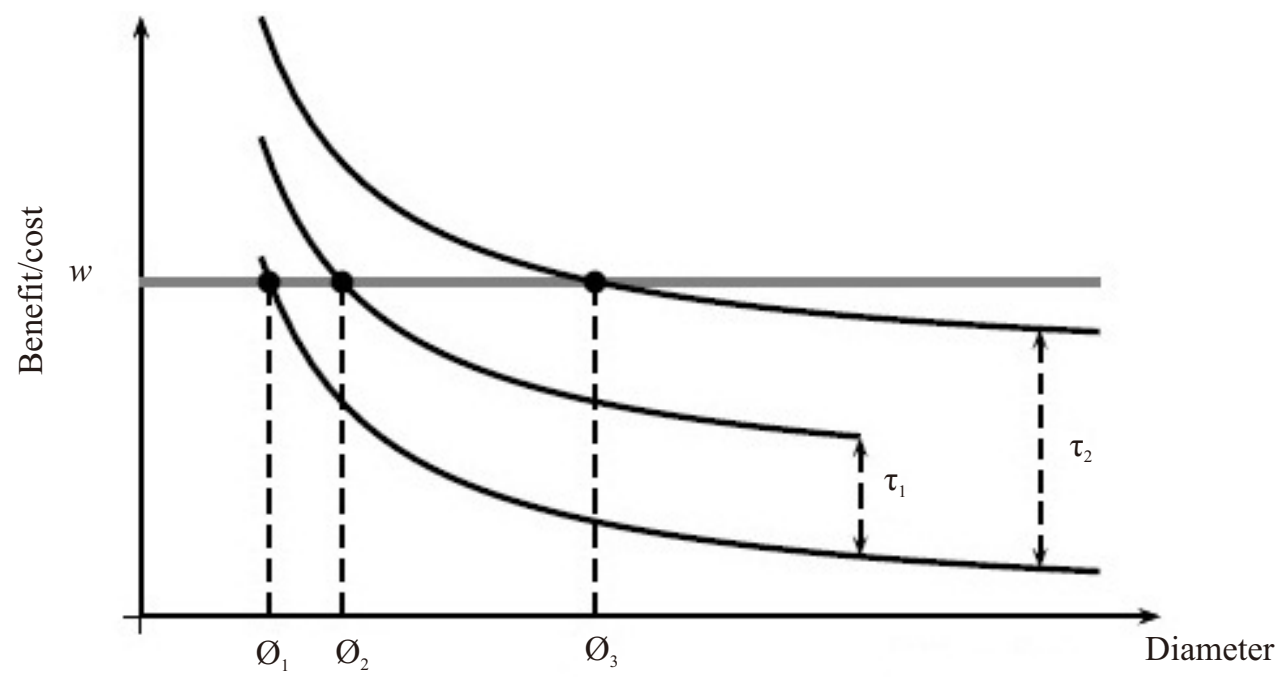

Figure 1 Effect of charge rate on the minimum diameter of timber that can be utilized economically.

applying the Leibnizrule to Equation [1] yields (Equation [2]).

$\frac{\partial\left(\phi_{i}(\tau)\right)}{\partial \tau}=\frac{\partial}{\partial \tau} \int_{\phi(\tau)}^{\infty} v(\phi) d \phi=-v\left(\phi_{i}(\tau)\right) \frac{\partial \phi_{i}}{\partial_{\tau}}$

$\frac{\partial \phi_{i}}{\partial_{\tau}} \geq 0 \quad \frac{\partial v\left(\phi_{i}(\tau)\right)}{\partial \tau}<0$

Since then . In other words, because the minimum diameter of the logs that can be utilized economically will increase with the higher tariffs, then the cumulative volume of timber that can be utilized becomes less. In sum, fees correlate positively with the amount of waste. This is consistent with what is given by Karsenty (2010) that the fee system can encourage appreciation for the resource by reducing waste and increasing the value of the product.

\section{Policy Implications}

The idea of raising PNBP through increasing DR rates uniformly could be counter-productive, in the sense of failing to raise non-tax revenues but instead increase logging waste. The increase of the DR rates can reduce the volume of timber that can be exploited economically. Increasing the minimum diameter of $\operatorname{logs}$ that can be exploited economically implicated in increased waste from logs. Thus, increasing the DR rates uniformly with the intention of increasing state revenue potentially produces double losses, the decreased efficiency of timber utilization and the possibility of declining revenues. State revenue from the DR, that is, $G$, is the product of the DR rate and volume of logs utilized. The volume of logs that can be used itself depends on the DR rate imposed. Thus, the expression for $\mathrm{G}$ can be stated as follows (Equatiot $\left.\left.\left.V\left(\phi_{i}\right]\right\rangle_{\bar{\tau}}\right)\right)$

Furthermore, to see the effect of the increase of the DR rates on state revenues $\mathrm{G}$ can be done by using the following $\underset{d \tau}{\operatorname{der} d \text { Gation }}=V\left(\phi_{i}^{\text {Equation }}(\tau)\right)+\tau \frac{4 \phi Y .}{\partial \phi} \frac{\partial \phi}{\partial \tau}$
Theoretically, the value of the Equation [4] can be negative, positive, or zero, depending on the DR rates at that time. Therefore, increasing DR rates may not necessarily result in increased state revenue. Differentiation of DR rates could increase state revenues and at the same time could increase the efficiency of logs utilization from natural forests. Here we get a double benefit, known as double dividends. It is similar with the tax assessment of gasoline in the US suggested by Glomm et al. ( 2008). Using Figure 2, this claim can be shown more easily. By using a single DR rate of $\tau_{2}$ the smallest diameter of $\log$ s that can be used is $\varnothing_{3}$, so the diameter of logs between $\varnothing_{1}$ and $\varnothing_{3}$ is unnecessarily wasted even though technically it is still possible to be processed. Logs with a diameter of between $\varnothing_{1}$ and $\varnothing_{3}$ will also not provide revenue for the government.

Now assume that the government is doing differentiation of DR rates, which is zero for logs with a diameter of between $\emptyset_{1}$ and $\varnothing_{2}, \tau_{1}$ for logs with a diameter of between $\emptyset_{2}$ and $\emptyset_{3}$, and $\tau_{2}$ for logs with a diameter of $\square \emptyset_{3}$. This scheme will change the curve of production cost per cubic meter of logs plus the DR rate of silky smooth passing from top left to bottom right to be broken, as indicated by the curve connecting the points $a, d, b, e, c$, and then follows the declining curve. In this way, the government will get additional revenue of $\tau_{1}\left[\mathrm{~V}\left(\varnothing_{2}\right)-\mathrm{V}\left(\varnothing_{3}\right)\right]$. Logs with a diameter of between $\varnothing_{1}$ and $\varnothing_{3}$ is no longer allowed to be a waste because it can provide benefits when used.

As already indicated above, the differentiation of DR rates potentially provide win-win solution; concessionary holders gain additional benefits, while the government gets additional revenue. Theoretically, if the permit holder and the government are rational, then the proposed DR payment of $\varphi>0$ by the licensee, for logs that have become waste so far, will be accepted by the government. Conversely, the 


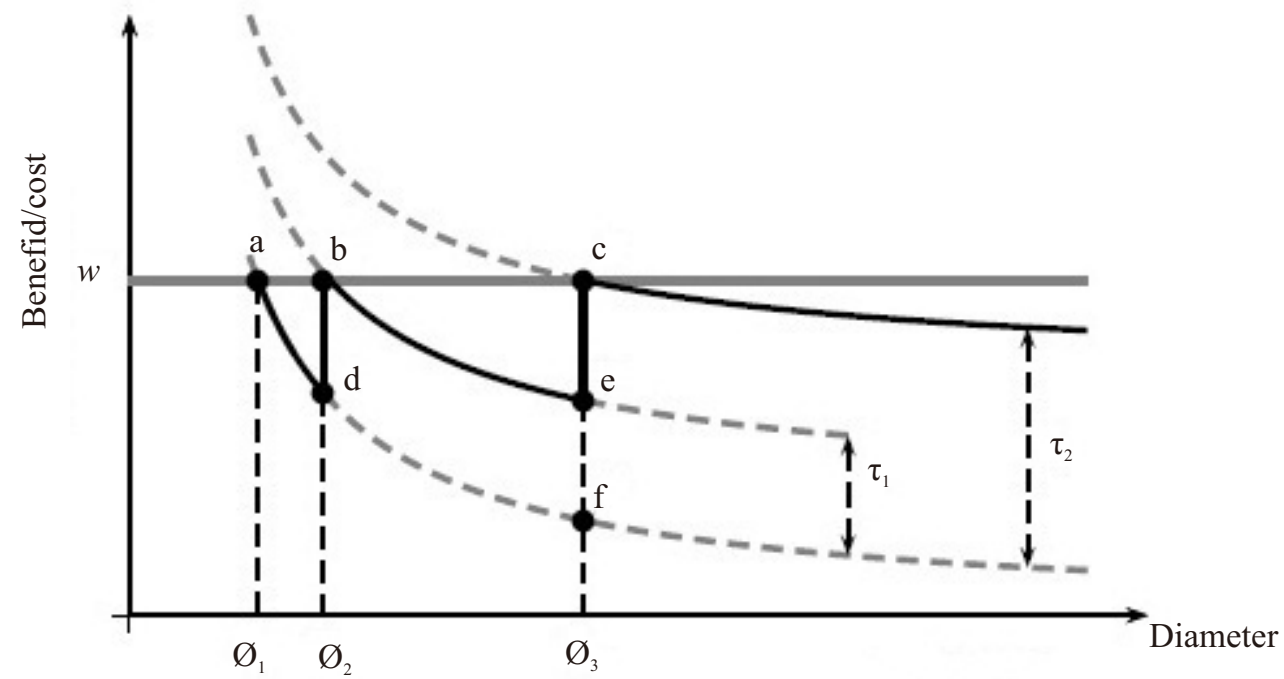

Figure 2 Effect of reforestasi fund (DR) tariff differentiation on efficiency of log utilization.

initiative may also come from the government by offering DR rates for small logs that is lower than the generally accepted DR rate. It is likely that the government's offer will be rejected by the license holders as it is still too high. But the government has no rational reason to reject the proposed DR rate of $\varphi>0$ because obviously better than not getting any. However, with this attitude, it is likely that timber which actually can produce higher-value products will be used as raw materials of lower value products. Things like this are also a form of inefficiency that also need to be avoided.

Differentiation of DR rates may also apply to the larger diameter. The point remains the same, i.e. the larger the timber the greater the diameter of the rent can be milked from them without causing inefficiency. Here win-win solution is not valid, but win-lose solution because of the increased revenue to the government is exactly the same as the reduction in profit from the license holder. However, in the public interest, the increase in levy rates for large diameter timber can be justified to the extent not kill the businesses who hold license.

Differentiation of the DR rates on logs from natural forests will add bureaucratic jobs, such as to check the production, which implies rising cost of bureaucracy. As pointed out by Posner (1975) and Leeson and Sobel (2008), first-degree price discrimination may lead to inefficiencies since implementing price discrimination raises the costs that are high as well. To avoid confusion, the differentiation and price discrimination charges have the same effect.

The most probable reaction of DR payer in response to tariff differentiation is to lower timber volume of large diameter and to increase timber volume of small diameter skewing behavior (Athey \& Levin 2001). By doing this, the same volume of timber will be charged with a lower DR so that it is detrimental to the state. To suppress the skewing behavior requires supervision by a bureaucracy which, of course, has implications for the increasing needs of the budget. Not to mention the possibility of collusion between the licensee and the government bureaucrats who carry out surveillance to obtain rents (Amacher 2006).

One approach to suppress skewing behavior and swelling budget to support the work of the bureaucracy is to carry out the classification of the structure of production, ie, the distribution of timber volumes by diameter class. By knowing the relationship between the structure of production with forest stand characteristics, the structure of production can be used as general guidelines in determining the amount of the DR to be paid for a particular harvest area. Collaborative research between expert interpretation of Landsat imagery and ecologists are very helpful in determining the relationship between forest stand characteristics and the structure of production.

\section{Conclusion}

In substance, the DR is not a continuation of the DJR. Continuation of DJR is substantially Performance Guarantee Fund, which has so far not been collected by the government. It is true, the conversion of a DR DJR has occurred. Relationship between the 2 stop there. DR rate determines the minimum diameter logs economical for use with positive correlation. Thus, an increase in DR rates uniformly on natural forest logs potentially produces more waste. Differentiation of DR rates on natural forest logs can improve the efficiency of timber utilization and increase state revenues - double dividend.

\section{Recommendation}

Policy assumptions of timber legality in private forests need to be re-examined, so that the gap between the texts of the legislation can be implemented based on the realities on the ground. 


\section{References}

Amacher GS. 2006. Corruption: A challenge for economists interested in forest policy design. Journal of Forest Economics 12(2):85-89. http://dx.doi.org/10.1016/ j.jfe.2006.05.002.

Amacher GS, Brazee RJ, \& Witvliet M. 2001. Royalty systems, government revenues, and forest condition: An application from Malaysia. Land Economics 77(2):300-313. http://dx.doi.org/10.2307/3147096.

Athey S \& Levin J. 2001. Information and competition in U.S. forest service timber auctions. Journal of Political Economy 109(2):375-417. http://dx.doi. org/10.1086/319558.

Broad R. 1995. The political economy of natural resources: Case studies of the Indonesian and Philippine forest sectors. The Journal of Developing Areas 29(3): 317-340.

Glomm G, Kawaguchi D, \& Sepulveda F. 2008. Green taxes and double dividends in a dynamic economy. Journal of Policy Modeling 30(1) 19-32. http://dx.doi.org/ 10.1016/j.jpolmod.2007.09.001.

Gray JW. 1983. Forest revenue systems in developing countries: their role in income generation and forest management strategies. FAO forestry paper 43 . Food and Agriculture Organization of the United Nations.

Hyde WF, Sedjo RA. 1992. Managing tropical forests: Reflections on the rent distribution discussion. 68(3): 343-350.
Karsenty A. 2010. Forest taxation regime for tropical forests: lessons from Central Africa. International Forestry Review 12(2):121-129. http://dx.doi.org/10.1505 lifor.12.2.121.

Laffont J, Martimort D. 2002. The Theory of Incentives: The Principal-Agent Model. Princeton paperbacks. Princeton: Princeton University Press.

Leeson PT, Sobel RS. 2008. Costly price discrimination. Economics Letters 99(1): 206-208. http://dx.doi.org/ 10.1016/j.econlet.2007.06.030.

Niskanen WA. 1968. The peculiar economics of bureaucracy. The American Economic Review 58(2): 293-305.

Paarsch HJ. 1993. The effect of stumpage rates on timber recovery. The Canadian Journal of Economics (Revue canadienne d'Economique) 26(1):107-120. http://dx.doi.org/10.2307/135847.

Poffenberger M. 1997. Rethinking Indonesian forest policy: Beyond the timber barons. Asian Survey 37(5): 453-469. http://dx.doi.org/10.2307/2645521.

Posner RA. 1975. The social costs of monopoly and regulation. Journal of Political Economy 83(4): 807-827. http://dx.doi.org/10.1086/260357.

World Bank. 2004. Proceedings of the International Workshop on Reforming Forest Fiscal Systems to Promote Poverty Reduction, and Sustainable Forest Management: October 19-21, 2003, World Bank, Washington. Number pt. 3. World Bank, PROFOR. 